\title{
Number of Implanted Stents May Predict Posttraumatic Stress Disorder in Patients With Acute Myocardial Infarction
}

\section{Guo-An Zhang}

Cardiovascular Center, People's Hospital of Shaanxi Province

\section{Chun-Hui He}

Department of Cardiology, Fuwai Hospital of CAMS

Zhong-Wei Liu

Cardiovascular Center, People's Hospital of Shaanxi Province

Shuo Pan

Cardiovascular Center, People's Hospital of Shaanxi Province

\section{Ting He}

Fuwai Hospital of CAMS

Xiu-Juan Zhao ( $\nabla$ zhaoxiujuan198512@163.com )

Northwest Womens and Childrens Hospital

\section{Xue-Mei Zhang}

Ultrasound Diagnostic Center, People's Hospital of Shaanxi Province

\section{Research}

Keywords: PTSD, acute myocardial infarction, stents, BNP, troponin I

Posted Date: December 11th, 2020

DOl: https://doi.org/10.21203/rs.3.rs-124309/v1

License: (c) (1) This work is licensed under a Creative Commons Attribution 4.0 International License. Read Full License 


\section{Abstract}

Background: This study is intended to explore the confounding factors associated with posttraumatic stress disorder (PTSD) in Chinese Han population with acute myocardial infarction (MI).

Methods: 300 acute MI patients were enrolled in this study, the demographic data, complicating diseases, medication, and perioperative procedures were documented. The PTSD was evaluated using the PTSD checklist-civilian version (PCL-C) scale one month after the occurrence of MI.

Results: 97 (32.3\%) patients were diagnosed as PTSD after finishing the PCL-C scale. The intra-aortic balloon pump (IABP) implantation and use of diuretic in PTSD patients with acute MI were significantly higher than those in non-PTSD patients with acute MI. The age, body mass index (BMI), heart rate, number of stents, urea nitrogen, white blood cells counts, creatine kinase-MB, myoglobin, troponin I, brain natriuretic peptide (BNP), total cholesterol, triglyceride, high-density lipoprotein-cholesterol, low-density lipoprotein-cholesterol, apolipoprotein A and apolipoprotein B were significantly and positively correlated with PTSD score (all $P<0.05$ ). After the adjustment of the confounding factors, the number of stents was significantly associated with PTSD in acute MI patients $(O R=4.131, P=0.003)$, meanwhile we also documented the troponin I and BNP were also significantly associated with PTSD in acute MI patients $(O R=1.066, P=0.046 ; O R=1.002, P=0.019$; respectively). The PTSD scores were $39.72 \pm 11.12,44.85 \pm$ $13.46,47.69 \pm 9.39$ and $49.33 \pm 18.14$ in acute MI patients with $1,2,3$ and 4 stents respectively $(P=$ $0.008)$.

Conclusion: The study found that the number of implanted stents may predict PTSD in Chinese Han patients with acute MI.

\section{Background}

Acute myocardial infarction (MI) is one of the deadly cardiovascular diseases affecting a great number of populations worldwide. It is estimated that 735,000 Americans had acute myocardial infarctions in US per year [1, 2]. In China, the mortality rates of acute MI have dramatically increased from 11.4 / 100,000 in 1987 to 64.25 / 100,000 in 2014 [3]. Previous literatures has documented that the severe medical diseases such as acute MI could trigger posttraumatic stress disorder (PTSD) [4]. According to previous literatures, the PTSD may reach $4-30 \%$ in patients who had myocardial infarction (MI) [5-7]. Furthermore, the PTSD was significantly associated with adverse cardiovascular outcome [8-10].

Some studies found that the association between PTSD and MI was independent of traditional MI risk factors, such as hypertension, diabetes and dyslipidemia [6,11-13]. The mechanisms of the association between PTSD and MI remain unclear, but underlying reasons might be multifactorial. Recent studies reported that inflammation [14], female gender [15, 16], Type D personality disorder [17, 18] and severity of disease $[7,16,19-22]$ played important roles in the occurrence and development of PTSD. However, the risk factors may be different since different ethnicity of the patients may react differently towards 
stress caused by MI. Therefore, this study is intended to explore the confounding factors associated with PTSD in Chinese Han population with acute MI.

\section{Methods}

\section{Subjects}

This cross-sectional study was performed from June of 2017 to December of 2019 in First Cardiology Department of Shaanxi Provincial Hospital. According to the power analysis formula $\mathrm{n}=2 p q\left(\mu_{a+} \mu_{\beta}\right)^{2} /\left(p_{1^{-}}\right.$ $\left.p_{0}\right)^{2}$, the sample size is estimated as $n=260$. In this case, a total of 300 patients with acute myocardial infarction (MI) which included both the ST-segment elevation myocardial infarction (STEMI) and non STsegment elevation myocardial infarction (NSTEMI) patients were enrolled in this present study. The acute MI was defined as the following: 1 . The MI patients must have symptoms such as chest, left arm, neck or tooth pain, or dyspnea; 2 . The occurrence the symptoms should be within 10 days; 3 . The electrocardiogram should show the ST-segment elevation or depression $\geq 0.1 \mathrm{mV}$, or inversed T wave or pathological Q wave in at least two leads. 4. The cardiac enzymes such as creatine kinase-MB (CK-MB), myoglobin or troponin I should increase according to the characteristics of each enzyme [23].

Among the 300 acute Ml patients, 215 (71.7\%) patients were men and $85(28.2 \%)$ patients were women. $194(64.7 \%)$ patients had STEMI while 106 (35.3\%) patients had NSTEMI. The average age of patients in this study was $60.34 \pm 11.80$ years. 97 (32.3\%) patients finished the follow up PTSD evaluation and were diagnosed as PTSD, 203 (67.7\%) patients were non-PTSD according to the PTSD scale.

The study was approved by ethic committee of People's Hospital of Shaanxi Province (Ethic Approval Number: 20170031). All participating subjects have signed the written voluntary informed consent form.

\section{PTSD evaluation}

The PTSD was evaluated using the PTSD Cheeklist-CivilianVersion (PCL-C) one month after the occurrence of MI. The patients were told to return to our hospital for follow up when they were discharged. During the follow up, the PCL-C scale was handed to the patients, the final scores were calculated and documented in excel files by two physicians. The PCL-C scale was the commonly used scale for the evaluation of post-traumatic experience in civilians. It included 17 items, the final score ranged from 17 to 85 points, each item has 5 answers representing 1-5 points. The 1 point was interpreted as "not at all", 2 points as "a little", 3 points as "moderate", 4 points as "very much", 5 points as "extremely". The 50-85 points were defined as PTSD in this present study [24, 25].

\section{Clinical data and blood tests}

Demographic data, complicating diseases, medication, and perioperative procedures were obtained from the medical and operational records. The systolic pressure, diastolic pressure and heart rate were measured by nurses after admission. The results of blood test were conducted 10 minutes within admission or the next morning of admission day, the blood samples were sent to Clinical Laboratory 
Department of Shaanxi Provincial Hospital for urea nitrogen, creatinine, WBC, white blood cells counts (WBC counts), red blood cells counts (RBC counts), hemoglobin, platelet counts, creatine kinase-MB (CKMB), myoglobin, troponin I, brain natriuretic peptide (BNP), total bilirubin (TBIL), Albumin, total cholesterol (TC), triglyceride, high-density lipoprotein-cholesterol (HDL-C), low-density lipoprotein-cholesterol (LDL-C), Apolipoprotein A, Apolipoprotein B, glycosylated hemoglobin A1C (HbA1C) detection using standard biochemical techniques [26].

\section{ECG and echocardiography}

ECG was performed 10 minutes within admission using Nihon Kohden ECG machine (ECG1350P). Classification of acute MI was mainly based on the ECG results. The ECG of STEMI showed ST-segment elevation $\geq 0.1 \mathrm{mV}$, or inversed T wave or pathological Q wave in at least two leads. NSTEMI showed STsegment depression $\geq 0.1 \mathrm{mV}$ in at least two leads [27].

The left ventricular ejection fraction (LVEF) was conducted using Doppler echocardiography 3 days within admission [28].

\section{Definition of risk factors}

Hypertension was defined as an average systolic blood pressure $\geq 140 \mathrm{~mm} \mathrm{Hg}$, or an average diastolic blood pressure $\geq 90 \mathrm{~mm} \mathrm{Hg}$, or both, or self-reported use of antihypertensive medication, or a selfreported history of hypertension.

Atrial fibrillation was diagnosed mainly via electrocardiogram (ECG) when admitted, characteristic findings included absence of $P$ waves and irregular R-R intervals.

Diabetes was defined as fasting plasma glucose $\geq 7.0 \mathrm{mmol} / \mathrm{L}$, or random plasma glucose $\geq$ $11.1 \mathrm{mmol} / \mathrm{L}$, or 2 hour plasma glucose in oral glucose tolerance test (OGTT) $\geq 11.1 \mathrm{mmol} / \mathrm{L}$, or use of insulin or oral hypoglycemic agents, or a self-reported history of diabetes [29].

\section{Statistical analysis}

The continuous variables were compared using Man-Whitney test, the categorical variables were compared using chi-square test or Fisher exact test. The correlation between the continuous variables and PTSD score was tested using Pearson simple linear correlation test. The continuous factors which showed difference between the two groups of population, and the factors which significantly correlated with PTSD score were enrolled in Logistic regression. The significantly different categorical variables were also enrolled in the Logistic regression for analysis. The PTSD score in acute MI patients with different number of stents implanted were compared using one-way ANOVA analysis, multiple testing correction is analyzed using LSD method. $P<0.05$ was considered as significant.

\section{Results}


Continuous variables of Non-PTSD patients and PTSD patients with acute MI were presented in Table 1. The age, heart rate, number of stents, urea nitrogen, WBC counts, CK-MB, myoglobin, Troponin I, BNP, TC, triglyceride, HDL-C, LDL-C, Apolipoprotein A and Apolipoprotein B were significantly higher in PTSD patients with acute Ml. than those in non-PTSD patients with acute MI. Meanwhile, the BMI, waist circumference, smoking index, systolic pressure, diastolic pressure, creatinine, RBC counts, hemoglobin, platelet counts, TBIL, albumin, HbA1c, LVEF were not significantly different in PTSD patients with acute $\mathrm{MI}$ and non-PTSD patients with acute MI. 
Table 1

Continuous variables of Non-PTSD patients and PTSD patients with acute MI

\begin{tabular}{|c|c|c|c|}
\hline & Non-PTSD $(n=203)$ & PTSD $(n=97)$ & $P$ value \\
\hline Age (years) & $58.92 \pm 11.29$ & $63.32 \pm 12.33$ & $0.006^{*}$ \\
\hline $\mathrm{BMI}\left(\mathrm{kg} / \mathrm{m}^{2}\right)$ & $24.49 \pm 2.91$ & $25.33 \pm 3.23$ & 0.055 \\
\hline Waist circumference $(\mathrm{cm})$ & $91.63 \pm 15.18$ & $92.04 \pm 14.62$ & 0.670 \\
\hline Smoking index & $292.44 \pm 401.91$ & $300.47 \pm 420.12$ & 0.966 \\
\hline Systolic pressure (mmHg) & $129.86 \pm 17.58$ & $131.54 \pm 22.19$ & 0.716 \\
\hline Diastolic pressure $(\mathrm{mmHg})$ & $79.19 \pm 11.11$ & $80.09 \pm 15.41$ & 0.964 \\
\hline Heart rate (beats/min) & $77.00 \pm 14.86$ & $81.06 \pm 15.69$ & $0.040 *$ \\
\hline Number of stents & $1.39 \pm 0.608$ & $1.75 \pm 0.80$ & $0.001^{*}$ \\
\hline Urea nitrogen (mmol/L) & $5.89 \pm 5.05$ & $6.03 \pm 2.14$ & $0.008^{*}$ \\
\hline Creatinine (umol/L) & $82.19 \pm 74.96$ & $76.24 \pm 28.71$ & 0.818 \\
\hline WBC counts $\left(\times 10^{9} / \mathrm{L}\right)$ & $8.66 \pm 2.75$ & $9.91 \pm 3.40$ & $0.001^{\star}$ \\
\hline RBC counts $\left(\times 10^{12} / \mathrm{L}\right)$ & $4.47 \pm 0.62$ & $4.54 \pm 0.63$ & 0.461 \\
\hline Hemoglobin $(\mathrm{g} / \mathrm{L})$ & $138.61 \pm 17.65$ & $139.72 \pm 21.52$ & 0.556 \\
\hline Platelet counts $\left(\times 10^{9} / \mathrm{L}\right)$ & $211.87 \pm 84.69$ & $227.14 \pm 78.40$ & 0.085 \\
\hline CK-MB (U/L) & $35.97 \pm 58.58$ & $85.34 \pm 95.37$ & $<0.001^{\star}$ \\
\hline Myoglobin (ug/L) & $206.22 \pm 413.80$ & $520.24 \pm 862.95$ & $<0.001 *$ \\
\hline Troponin I (ug/L) & $5.08 \pm 10.39$ & $16.96 \pm 18.38$ & $<0.001^{*}$ \\
\hline $\mathrm{BNP}(\mathrm{pg} / \mathrm{mL})$ & $359.38 \pm 516.46$ & $590.67 \pm 762.50$ & $0.003^{*}$ \\
\hline TBIL (umol/L) & $21.05 \pm 16.83$ & $18.68 \pm 11.49$ & 0.164 \\
\hline Albumin $(\mathrm{g} / \mathrm{L})$ & $37.12 \pm 3.48$ & $38.29 \pm 5.78$ & 0.110 \\
\hline $\mathrm{TC}(\mathrm{mmol} / \mathrm{L})$ & $3.73 \pm 0.90$ & $4.99 \pm 1.11$ & $<0.001^{*}$ \\
\hline Triglyceride (mmol/L) & $1.59 \pm 1.07$ & $1.87 \pm 1.03$ & $<0.001^{*}$ \\
\hline $\mathrm{HDL}-\mathrm{C}(\mathrm{mmol} / \mathrm{L})$ & $0.96 \pm 0.21$ & $1.14 \pm 0.30$ & $<0.001^{*}$ \\
\hline \multicolumn{4}{|c|}{$\begin{array}{l}\text { Note: } P T S D \text { Post-Traumatic Stress Disorder, } M I \text { Myocardial Infarction, } B M / \text { body mass index, } W B C \\
\text { White Blood Cells, } R B C \text { Red Blood Cells, } C K-M B \text { Creatine Kinase-MB, } B N P \text { Brain Natriuretic Peptide, } \\
T B I L \text { Total Bilirubin, TC Total Cholesterol, } H D L-C \text { High-Density Lipoprotein-Cholesterol, } L D L-C L \text { Low- } \\
\text { Density Lipoprotein-Cholesterol, } H b A 1 C \text { glycosylated Hemoglobin A1c, } L V E F \text { left ventricular ejection } \\
\text { fraction, } \star P<0.05\end{array}$} \\
\hline
\end{tabular}




\begin{tabular}{|c|c|c|c|}
\hline & Non-PTSD $(n=203)$ & PTSD (n = 97) & $P$ value \\
\hline LDL-C (mmol/L) & $2.25 \pm 0.75$ & $3.17 \pm 0.87$ & $<0.001^{*}$ \\
\hline Apolipoprotein A (g/L) & $1.09 \pm 0.21$ & $1.22 \pm 0.27$ & $<0.001^{*}$ \\
\hline Apolipoprotein B (g/L) & $0.81 \pm 0.20$ & $1.04 \pm 0.23$ & $<0.001^{\star}$ \\
\hline HbA1c (\%) & $6.13 \pm 1.38$ & $6.29 \pm 1.59$ & 0.190 \\
\hline LVEF (\%) & $55.13 \pm 8.69$ & $53.73 \pm 10.71$ & 0.544 \\
\hline PTSD score & $36.08 \pm 7.81$ & $57.46 \pm 6.63$ & $<0.001^{*}$ \\
\hline \multicolumn{4}{|c|}{$\begin{array}{l}\text { Note: } P T S D \text { Post-Traumatic Stress Disorder, } M I \text { Myocardial Infarction, } B M / \text { body mass index, } W B C \\
\text { White Blood Cells, } R B C \text { Red Blood Cells, } C K-M B \text { Creatine Kinase-MB, } B N P \text { Brain Natriuretic Peptide, } \\
T B I L \text { Total Bilirubin, } T C \text { Total Cholesterol, } H D L-C \text { High-Density Lipoprotein-Cholesterol, } L D L-C \text { Low- } \\
\text { Density Lipoprotein-Cholesterol, } H b A 1 C \text { glycosylated Hemoglobin A1c, } L V E F \text { left ventricular ejection } \\
\text { fraction, }{ }^{*} P<0.05\end{array}$} \\
\hline
\end{tabular}

Categorical variables of Non-PTSD patients and PTSD patients with acute MI were presented in Table 2. The IABP implantation and use of diuretic in PTSD patients with acute MI were significantly higher than those in non-PTSD patients with acute MI. While the sex, hypertension, atrial fibrillation, diabetes mellitus, classification of $\mathrm{Ml}$, primary $\mathrm{PCl}$, thrombus aspiration, stent implantation, temporary pacemaker implantation, aspirin, clopidogrel, ticagrelor, tirofiban, norepinephrine, dopamine, calcium, antagonist, $\beta$ blockers ACEI/ARB, nitrates, intracoronary sodium nitroprusside and intracoronary urokinase showed no significant difference in PTSD patients with acute MI and non-PTSD patients with acute MI. 
Table 2

Categorical variables of Non-PTSD patients and PTSD patients with acute MI

\begin{tabular}{|c|c|c|c|}
\hline & Non-PTSD $(n=203)$ & PTSD ( $n=97)$ & $P$ value \\
\hline Sex $(\%)$ & & & 0.491 \\
\hline men & $148(72.9 \%)$ & $67(69.1 \%)$ & \\
\hline women & $55(27.1 \%)$ & $30(30.9 \%)$ & \\
\hline Hypertension (\%) & $109(53.7 \%)$ & $51(52.6 \%)$ & 0.856 \\
\hline Atrial fibrillation (\%) & $5(2.5 \%)$ & $2(2.1 \%)$ & 1.000 \\
\hline Diabetes mellitus (\%) & $39(19.2 \%)$ & $20(20.6 \%)$ & 0.774 \\
\hline Classification of MI (\%) & & & 0.222 \\
\hline STEMI & $136(67.0 \%)$ & $58(59.8 \%)$ & \\
\hline NSTEMI & $67(33.0 \%)$ & $39(40.2 \%)$ & \\
\hline Primary PCI (\%) & $37(18.2 \%)$ & $11(11.3 \%)$ & 0.128 \\
\hline Thrombus aspiration (\%) & $20(9.9 \%)$ & $7(7.2 \%)$ & 0.456 \\
\hline Stent implantation (\%) & $140(69.7 \%)$ & $59(60.8 \%)$ & 0.130 \\
\hline IABP implantation (\%) & $8(3.9 \%)$ & $13(13.4 \%)$ & $0.003^{*}$ \\
\hline Temporary pacemaker implantation (\%) & $16(7.9 \%)$ & $6(6.2 \%)$ & 0.598 \\
\hline Aspirin (\%) & $203(100 \%)$ & $97(100 \%)$ & 1.000 \\
\hline Clopidogrel (\%) & $185(91.1 \%)$ & $89(91.8 \%)$ & 0.858 \\
\hline Ticagrelor (\%) & $65(32.0 \%)$ & $28(28.9 \%)$ & 0.581 \\
\hline Tirofiban (\%) & $67(33.0 \%)$ & $26(26.8 \%)$ & 0.277 \\
\hline Norepinephrine (\%) & $28(13.8 \%)$ & $8(8.2 \%)$ & 0.176 \\
\hline Dopamine (\%) & $19(9.4 \%)$ & $9(9.3 \%)$ & 0.982 \\
\hline Calcium antagonist (\%) & $24(11.8 \%)$ & $8(8.2 \%)$ & 0.348 \\
\hline$\beta$-blockers (\%) & $179(88.2 \%)$ & $86(88.7 \%)$ & 0.903 \\
\hline ACEI/ARB (\%) & $174(85.7 \%)$ & $85(87.6 \%)$ & 0.752 \\
\hline Diuretic (\%) & 66 (32.5\%) & 45 (46.4\%) & $0.020^{*}$ \\
\hline
\end{tabular}

Note: PTSD Post-Traumatic Stress Disorder, MIMyocardial Infarction, STEMIST-segment Elevation Myocardial Infarction, NSTEMINon ST-segment Elevation Myocardial Infarction, $P C /$ Percutaneous Coronary Intervention, IABP Intra-Aortic Balloon Pump, ACEI Angiotension Converting Enzyme Inhibitor, $A R B$ Angiotensin Receptor Blockers, ${ }^{\star} P<0.05$ 


\begin{tabular}{|c|c|c|c|}
\hline & Non-PTSD $(n=203)$ & PTSD (n = 97) & $P$ value \\
\hline Nitrates (\%) & $134(66.0 \%)$ & $68(70.1 \%)$ & 0.480 \\
\hline Intracoronary sodium nitroprusside (\%) & $12(5.9 \%)$ & $8(8.2 \%)$ & 0.448 \\
\hline Intracoronary urokinase (\%) & $2(1.0 \%)$ & $0(0.0 \%)$ & 1.000 \\
\hline \multicolumn{4}{|c|}{$\begin{array}{l}\text { Note: PTSD Post-Traumatic Stress Disorder, MIMyocardial Infarction, STEMIST-segment Elevation } \\
\text { Myocardial Infarction, NSTEMINon ST-segment Elevation Myocardial Infarction, PCI Percutaneous } \\
\text { Coronary Intervention, IABP Intra-Aortic Balloon Pump, ACEI Angiotension Converting Enzyme } \\
\text { Inhibitor, ARB Angiotensin Receptor Blockers, }{ }^{\star} P<0.05\end{array}$} \\
\hline
\end{tabular}

Pearson correlation analysis between PTSD score and continuous confounding factors in patients with acute $\mathrm{MI}$ were in Table 3. The age, BMI, heart rate, number of stents, urea nitrogen, WBC counts, CK-MB, myoglobin, Troponin I, BNP, TC, triglyceride, HDL-C, LDL-C, apolipoprotein A and apolipoprotein B were significantly and positively correlated with PTSD score. Meanwhile, the waist circumference, smoking index, systolic pressure, diastolic pressure, creatinine, RBC counts, hemoglobin, platelet counts, TBIL, albumin, HbA1c and LVEF were not linearly correlated with PTSD score in our population. 
Table 3

Pearson correlation analysis between PTSD score and continuous confounding factors in patients with acute $\mathrm{MI}$

\begin{tabular}{|c|c|c|}
\hline & $r$ & $P$ value \\
\hline Age & 0.233 & $<0.001^{*}$ \\
\hline BMI & 0.125 & $0.030 *$ \\
\hline Waist circumference & -0.058 & 0.318 \\
\hline Smoking index & 0.038 & 0.516 \\
\hline Systolic pressure & 0.084 & 0.149 \\
\hline Diastolic pressure & 0.041 & 0.483 \\
\hline Heart rate & 0.141 & $0.015^{\star}$ \\
\hline Number of stents & 0.236 & $0.001^{*}$ \\
\hline Urea nitrogen & 0.131 & $0.024 *$ \\
\hline Creatinine & 0.004 & 0.940 \\
\hline WBC counts & 0.147 & $0.011 *$ \\
\hline RBC counts & -0.050 & 0.385 \\
\hline Hemoglobin & -0.078 & 0.176 \\
\hline Platelet counts & 0.057 & 0.328 \\
\hline CK-MB & 0.304 & $<0.001$ * \\
\hline Myoglobin & 0.271 & $<0.001^{*}$ \\
\hline Troponin I & 0.421 & $<0.001 *$ \\
\hline BNP & 0.278 & $<0.001 *$ \\
\hline TBIL & -0.101 & 0.088 \\
\hline Albumin & 0.110 & 0.063 \\
\hline TC & 0.546 & $<0.001^{*}$ \\
\hline Triglyceride & 0.136 & $0.022^{\star}$ \\
\hline HDL-C & 0.323 & $<0.001 *$ \\
\hline
\end{tabular}

Note: PTSD Post-Traumatic Stress Disorder, $M I$ Myocardial Infarction, $B M /$ body mass index, WBC White Blood Cells, $R B C$ Red Blood Cells, $C K-M B$ Creatine Kinase-MB, $B N P$ Brain Natriuretic Peptide, TBIL Total Bilirubin, TC Total Cholesterol, HDL-C High-Density Lipoprotein-Cholesterol, LDL-C LowDensity Lipoprotein-Cholesterol, HbA1c glycosylated Hemoglobin A1c, LVEF left ventricular ejection fraction, $* P<0.05$ 


\begin{tabular}{|c|c|c|}
\hline & $r$ & $P$ value \\
\hline LDL-C & 0.517 & $<0.001^{*}$ \\
\hline Apolipoprotein A & 0.235 & $<0.001^{\star}$ \\
\hline Apolipoprotein B & 0.502 & $<0.001^{\star}$ \\
\hline $\mathrm{HbA1c}$ & 0.054 & 0.436 \\
\hline LVEF & -0.105 & 0.094 \\
\hline \multicolumn{3}{|c|}{$\begin{array}{l}\text { Note: } P T S D \text { Post-Traumatic Stress Disorder, } M I \text { Myocardial Infarction, } B M I \text { body mass index, WBC } \\
\text { White Blood Cells, RBCRed Blood Cells, } C K-M B \text { Creatine Kinase-MB, } B N P \text { Brain Natriuretic Peptide, } \\
\text { TBIL Total Bilirubin, TC Total Cholesterol, } H D L-C \text { High-Density Lipoprotein-Cholesterol, } L D L-C \text { Low- } \\
\text { Density Lipoprotein-Cholesterol, } H b A 1 c \text { glycosylated Hemoglobin A1c, } L V E F \text { left ventricular ejection } \\
\text { fraction, } \star P<0.05\end{array}$} \\
\hline
\end{tabular}

Logistic regression analysis for PTSD using confounding factors in patients with acute MI was in Table 4. The continuous factors which showed difference between the two groups of population, and the factors which significantly correlated with PTSD score were enrolled in Logistic regression, the significantly different categorical variables were also enrolled in the Logistic regression for analysis. After the adjustment of the confounding factors, the number of stents was significantly associated with PTSD in acute MI patients $(O R=4.131, P=0.003)$, meanwhile we also documented the Troponin I and BNP were also significantly associated with PTSD in acute MI patients $(O R=1.066, P=0.046 ; O R=1.002, P=0.019$; respectively). 
Table 4

Logistic regression analysis for PTSD using confounding factors in patients with acute MI

\begin{tabular}{|c|c|c|c|}
\hline & OR & $95 \% \mathrm{Cl}$ & $P$ value \\
\hline Age & 1.076 & $0.996-1.163$ & 0.063 \\
\hline Heart rate & 0.987 & $0.942-1.035$ & 0.597 \\
\hline Number of stents & 4.131 & $1.599-10.677$ & $0.003^{\star}$ \\
\hline IABP implantation & 7.406 & $0.792-69.290$ & 0.079 \\
\hline Diuretic & 0.399 & $0.080-1.998$ & 0.263 \\
\hline Urea nitrogen & 1.028 & $0.903-1.171$ & 0.673 \\
\hline WBC & 0.871 & $0.642-1.182$ & 0.374 \\
\hline CK-MB & 1.008 & $0.993-1.022$ & 0.296 \\
\hline Myoglobin & 1.001 & $1.000-1.002$ & 0.249 \\
\hline Troponin I & 1.066 & $1.001-1.136$ & $0.046^{*}$ \\
\hline BNP & 1.002 & $1.000-1.003$ & $0.019 *$ \\
\hline TC & 3.481 & $0.475-25.54$ & 0.220 \\
\hline Triglyceride & 1.471 & $0.537-4.029$ & 0.453 \\
\hline HDL-C & 0.277 & $0.001-233.404$ & 0.709 \\
\hline LDL-C & 0.594 & $0.077-4.604$ & 0.618 \\
\hline Apolipoprotein A & 23.429 & $0.046-11949.87$ & 0.321 \\
\hline Apolipoprotein B & 224.563 & $0.178-283219.66$ & 0.137 \\
\hline \multicolumn{4}{|c|}{$\begin{array}{l}\text { Note: } P T S D \text { Post-Traumatic Stress Disorder, MIMyocardial Infarction, } C / \text { Confidence Interval, IABP } \\
\text { Intra-Aortic Balloon Pump, WBCWhite Blood Cells, CK-MB Creatine Kinase-MB, BNP Brain Natriuretic } \\
\text { Peptide, TC Total Cholesterol, } H D L-C \text { High-Density Lipoprotein-Cholesterol, } L D L-C \text { Low-Density } \\
\text { Lipoprotein-Cholesterol, * } P<0.05\end{array}$} \\
\hline
\end{tabular}

PTSD score in acute MI patients with different number of stents implanted were presented in Fig. 1. The PTSD score showed the increase trend as the number of stents implanted increased, the PTSD score were $39.72 \pm 11.12,44.85 \pm 13.46,47.69 \pm 9.39$ and $49.33 \pm 18.14$ in acute MI patients with 1, 2, 3 and 4 stents respectively. The PTSD score showed significant difference in acute MI patients with different number of stents implanted $(P=0.008)$. The comparison between the groups showed that the significant difference of PTSD scores may come from the PTSD scores variation in patients with 1 stent vs. 2 stents $(P=$ 0.006), and also in patients with 1 stent vs. 3 stents $(P=0.023)$.

\section{Discussion}


Our study showed that the incidence of PTSD in acute MI patients was $32.3 \%$. This incidence in acute MI patients was much higher than the general population, whose prevalence of PTSD were $10 \%-12 \%$ in men and $5 \%-6 \%$ in women [6]. Our result was consistent with study by Rocha et al, he had reported the prevalence of PTSD after acute MI was 30\% [7]. However, one meta-analysis investigated 24 observational cross-sectional studies, they found the prevalence was $12 \%$ [8]. The difference may be originated from the scale of PTSD, the self-reported questionnaires may lead to an elevated prevalence of the disease. In contrast, when the specific diagnostic scales requiring more strict structured interviews were applied, the prevalence may be lower [15]. However, the controversy remained that some researcher thought the PTSD was under-diagnosed since most patients may not want to recall the painful experience [30].

Interestingly, the number of implanted stents was significantly associated with PTSD in acute MI patients after the adjustment of the confounding factors $(O R=4.131, P=0.003)$. Meanwhile, we found that the PTSD score showed the increase trend as the number of stents implanted increased, the PTSD score were $39.72 \pm 11.12,44.85 \pm 13.46,47.69 \pm 9.39$ and $49.33 \pm 18.14$ in acute MI patients with $1,2,3$ and 4 stents respectively. Meanwhile, we also found that the significant difference of PTSD scores may mainly come from the PTSD scores in patients with 1 stent vs. 2 stents $(P=0.006)$, and also in patients with 1 stent vs. 3 stents $(P=0.023)$. The number of implanted stents was rarely documented as risk factors in previous studies. The mechanism of the association was still unclear. The possible reasons may be as follows. First, the principle of the primary $\mathrm{PCl}$ is to open the coronary artery and maintain the blood perfusion in the coronary artery, the procedure should be as simple as possible. The implantation of multiple stents increases the complexity of $\mathrm{PCl}$ and the possibility of coronary slow flow phenomenon or no-reflow phenomenon, it is usually avoided in primary PCI [31,32]. However, the stents should be implanted if the patients have the multiple vessels lesion and cardiac shock, the complete revascularization might benefit the patients and save the lives of the patients with severe lesions [33, 34]. To some extent, the implantation of multiple stents usually indicated long and diffused lesion or multiple vessel lesions in patients with cardiac shock, the severity of disease may increase the PTSD experience. So the implantation of more than 1 stent showed significant increased PTSD scores according to the multiple testing corrections. Second, China is still developing country and the coverage of the medical expenses was not sufficient $[35,36]$, the significantly higher medical expenses caused by the multiple stents implantation may leave the patients and their family a great amount of debt. It served as a daily reminder of stress experienced in the hospital and repeated consideration of it may contribute to the PTSD levels.

In this present study, we have used the myoglobin, CK-MB, and Troponin I as the cardiac injury biomarkers. The three biomarkers were all significantly correlated with PTSD score, the biomarker with highest correlation efficient was Troponin I $(r=0.421)$, followed by CK-MB $(r=0.304)$ and myoglobin ( $r=$ 0.271) (all $P<0.001$ ). Studies have shown that the amounts of plasma biomarkers such as Troponin I, myoglobin, CK-MB were reported to be closely associated with infarcted myocardium size. Then the cardiac infarction size strongly predicted the LVEF, heart failure, short and long-term outcome and after myocardial infarction [37-39]. Therefore, it is easy to understand that elevation of cardiac injury biomarkers may reflect the prognosis of the patients, causing the occurrence of the PTSD experience. 
After the adjustment of other confounding factors, the Troponin I was the only cardiac injury biomarker associated with PTSD $(O R=1.066, P=0.046)$. The specific reason was not clear yet, the characteristics such its short reactive time and long endurance time making it a better predictor of myocardia necrosis and severity of the disease than CK-MB and myoglobin [40].

The BNP was also found to be significantly associated with PTSD in acute MI patients $(O R=1.002, P=$ $0.019)$. BNP has a strong prognostic ability in chronic heart failure after an acute coronary syndrome [41, 42]. BNP elevation was reported to correlate with increased mortality of patients with ACS regardless of left ventricular function [43]. BNP levels increase shortly after the occurrence of symptoms in ACS patients [44], then the symptom of dyspnea may cause painful experience and finally lead to PTSD.

The strength of this study is that we have included 29 continuous and 23 categorical confounding factors in the study, especially the perioperative medication and operational procedures and $\mathrm{PCl}$ information, we discovered that the number of implanted stents was associated with PTSD in acute MI patients in for the first time. Second, we have adopted three cardiac injury biomarkers with apparent difference features in reactive time, peak time, and endurance time, and found that the troponin I was associated with PTSD after adjustments. The study also has several limitations, the cross section design of the study could determine the causal relationship between the PTSD and acute MI. Second, the population we rerolled was all MI patients in our department, the prevalence of PTSD could not be calculated. Third, the age and IABP implantation had the borderline significance $(P=0.063$ and $P=0.079$, respectively), they might be significantly associated with PTSD if the sample size was enlarged.

\section{Conclusion}

In conclusion, the study found that the number of implanted stents, BNP and troponin I were significantly associated with PTSD in Chinese Han patients with acute MI. Meanwhile, the significant difference of PTSD scores may mainly come from the PTSD scores in patients with 1 stent vs. 2 stents and 3 stents. Since Pedersen et al. found that the prevalence may decrease over time [45], but Abbas et al found that PTSD occurred in up to two-third of the acute MI patients if the follow-up was long enough [46]. Further studies may investigate the association with long period follow-up time.

\section{Abbreviations}

ACEl: angiotension converting enzyme inhibitor; ARB: angiotensin receptor blockers; BMI: body mass index; BNP: brain natriuretic peptide; CK-MB: creatine kinase-MB; HbA1c: glycosylated hemoglobin A1c; HDL-C: high-density lipoprotein-cholesterol; IABP: intra-aortic balloon pump; LDL-C: low-density lipoprotein-cholesterol; LVEF: left ventricular ejection fraction; MI: myocardial infarction; NSTEMI: non STsegment elevation myocardial infarction; PCl: percutaneous coronary intervention; PTSD: post-traumatic stress disorder; RBC: red blood cells; STEMI: ST-segment elevation myocardial infarction; TBIL: total bilirubin; TC: total cholesterol; WBC: white blood cells. 


\section{Declarations}

\section{Authors' contributions}

Conceived and designed the experiments: G-AZ, X-JZ. Performed the experiments: G-AZ, C-HH, Z-WL, SP, TH, X-JZ. Collected the data: G-AZ, C-HH, Z-WL, SP, TH. Analyzed the data: X-JZ X-MZ, C-HH. Wrote the manuscript: X-JZ.

\section{Funding}

The study was funded by Innovative Talents Promotion Project of Shaanxi Province (Nos. 2020KJXX086).

\section{Availability of data and materials}

Data and material were available on request.

\section{Patient consent}

The consents were signed by all recruited patients.

\section{Ethics approval}

The study was approved by the ethics committee of People's Hospital of Shaanxi Province. The authors assert that all procedures contributing to this work comply with the ethical standards of the relevant national and institutional committees on human experimentation and with the Helsinki Declaration of 1975 , as revised in 2008 . The authors assert that all procedures contributing to this work comply with the ethical standards of the relevant national and institutional guides.

\section{Consent for publication}

All authors have approved the final manuscript for publication.

\section{Competing interests}

The authors declare that they have no competing interests.

\section{References}

1. Chatterjee P, Joynt Maddox KE. US National Trends in Mortality From Acute Myocardial Infarction and Heart Failure: Policy Success or Failure? JAMA Cardiol. 2018; 3:336-340.

2. Mozaffarian D, Benjamin EJ, Go AS, Arnett DK, Blaha MJ, Cushman M, et al. Heart disease and stroke statistics-2015 update: a report from the American Heart Association. Circulation. 2015; 131:e29322. 
3. Chang J, Liu X, Sun Y. Mortality due to acute myocardial infarction in China from 1987 to 2014: Secular trends and age-period-cohort effects. Int J Cardiol. 2017; 227:229-238.

4. Tedstone JE, Tarrier N. Posttraumatic stress disorder following medical illness and treatment. Clin Psychol Rev. 2003; 23:409-448.

5. Edmondson D, Richardson S, Falzon L, Davidson KW, Mills MA, Neria Y. Posttraumatic stress disorder prevalence and risk of recurrence in acute coronary syndrome patients: a meta-analytic review. PLoS One. 2012; 7:e38915.

6. Vaccarino V, Goldberg J, Rooks C, Shah AJ, Veledar E, Faber TL, et al. Post-traumatic stress disorder and incidence of coronary heart disease: a twin study. J Am Coll Cardiol. 2013; 62:970-978.

7. Rocha LP, Peterson JC, Meyers B, Boutin-Foster C, Charlson ME, Jayasinghe N, et al. Incidence of posttraumatic stress disorder (PTSD) after myocardial infarction (MI) and predictors of ptsd symptoms post-Ml--a brief report. Int J Psychiatry Med. 2008; 38:297-306.

8. von Känel R, Hari R, Schmid JP, Wiedemar L, Guler E, Barth J, et al. Non-fatal cardiovascular outcome in patients with posttraumatic stress symptoms caused by myocardial infarction. J Cardiol. 2011; 58:61-68.

9. Edmondson D, Rieckmann N, Shaffer JA, Schwartz JE, Burg MM, Davidson KW, et al. Posttraumatic stress due to an acute coronary syndrome increases risk of 42-month major adverse cardiac events and all-cause mortality. J Psychiatr Res. 2011; 45:1621-1626.

10. Tsutsui T, Tanaka H, Nishida A, Asukai N. Posttraumatic stress symptoms as predictive of prognosis after acute coronary syndrome. Gen Hosp Psychiatry. 2017; 45:56-61.

11. Bedi US, Arora R. Cardiovascular manifestations of posttraumatic stress disorder. J Natl Med Assoc. 2007; 99:642-649.

12. Kubzansky LD, Koenen KC, Spiro A, 3rd, Vokonas PS, Sparrow D. Prospective study of posttraumatic stress disorder symptoms and coronary heart disease in the Normative Aging Study. Arch Gen Psychiatry. 2007; 64:109-116.

13. Sumner JA, Chen Q, Roberts AL, Winning A, Rimm EB, Gilsanz P, et al. Cross-Sectional and Longitudinal Associations of Chronic Posttraumatic Stress Disorder With Inflammatory and Endothelial Function Markers in Women. Biol Psychiatry. 2017; 82:875-884.

14. Bielas H, Meister-Langraf RE, Schmid JP, Barth J, Znoj H, Schnyder U, et al. C-reactive protein as a predictor of posttraumatic stress induced by acute myocardial infarction. Gen Hosp Psychiatry. 2018; 53:125-130.

15. Roberge MA, Dupuis G, Marchand A. Post-traumatic stress disorder following myocardial infarction: prevalence and risk factors. Can J Cardiol. 2010; 26:e170-175.

16. Hari R, Begré S, Schmid JP, Saner H, Gander ML, von Känel R. Change over time in posttraumatic stress caused by myocardial infarction and predicting variables. J Psychosom Res. 2010; 69:143150.

17. Bostwick JM, Sola CL. An updated review of implantable cardioverter/defibrillators, induced anxiety, and quality of life. Psychiatr Clin North Am. 2007; 30:677-688. 
18. Chung MC, Dennis I, Berger Z, Jones R, Rudd H. Posttraumatic stress disorder following myocardial infarction: personality, coping, and trauma exposure characteristics. Int J Psychiatry Med. 2011; 42:393-419.

19. Whitehead DL, Perkins-Porras L, Strike PC, Steptoe A. Post-traumatic stress disorder in patients with cardiac disease: predicting vulnerability from emotional responses during admission for acute coronary syndromes. Heart. 2006; 92:1225-1229.

20. Ginzburg K, Solomon Z, Koifman B, Keren G, Roth A, Kriwisky M, et al. Trajectories of posttraumatic stress disorder following myocardial infarction: a prospective study. J Clin Psychiatry. 2003; 64:12171223.

21. Pedersen SS, Middel B, Larsen ML. Posttraumatic stress disorder in first-time myocardial infarction patients. Heart Lung. 2003; 32:300-307.

22. Guler E, Schmid JP, Wiedemar L, Saner H, Schnyder U, von Känel R. Clinical diagnosis of posttraumatic stress disorder after myocardial infarction. Clin Cardiol. 2009; 32:125-129.

23. Thygesen K, Alpert JS, Jaffe AS, Chaitman BR, Bax JJ, Morrow DA, et al. Fourth Universal Definition of Myocardial Infarction (2018). Circulation. 2018; 138:e618-e651.

24. Alhalal E, Ford-Gilboe M, Wong C, AlBuhairan F. Reliability and validity of the Arabic PTSD Checklist Civilian Version (PCL-C) in women survivors of intimate partner violence. Res Nurs Health. 2017; 40:575-585.

25. Hatch R, Young D, Barber V, Griffiths J, Harrison DA, Watkinson P. Anxiety, Depression and Post Traumatic Stress Disorder after critical illness: a UK-wide prospective cohort study. Crit Care. 2018; 22:310.

26. Pan S, Liu ZW, Lv Y, Song WQ, Ma X, Guan GC, et al. Association between neutrophilic granulocyte percentage and depression in hospitalized patients with heart failure. BMC Psychiatry. 2016; 16:446.

27. Chen BD, Chen XC, Yang YN, Gao XM, Ma X, Huang Y, et al. Apolipoprotein A1 is associated with SYNTAX score in patients with a non-ST segment elevation myocardial infarction. Lipids Health Dis. 2019; 18:159.

28. Pan S, Liu ZW, Shi S, Ma X, Song WQ, Guan GC, et al. Hamilton rating scale for depression-24 (HAM$\mathrm{D}(24))$ as a novel predictor for diabetic microvascular complications in type 2 diabetes mellitus patients. Psychiatry Res. 2017; 258:177-183.

29. Pan S, Guan GC, Lv Y, Liu ZW, Liu FQ, Zhang Y, et al. G-T haplotype established by rs3785889rs16941382 in GOSR2 gene is associated with coronary artery disease in Chinese Han population. Oncotarget. 2017; 8:82165-82173.

30. Gander ML, von Känel R. Myocardial infarction and post-traumatic stress disorder: frequency, outcome, and atherosclerotic mechanisms. Eur J Cardiovasc Prev Rehabil. 2006; 13:165-172.

31. Cenko E, Ricci B, Kedev S, Kalpak O, Câlmâc L, Vasiljevic Z, et al. The no-reflow phenomenon in the young and in the elderly. Int J Cardiol. 2016; 222:1122-1128.

32. Li H, Fu DG, Liu FY, Zhou H, Li XM. Evaluation of related factors, prediction and treatment drugs of no-reflow phenomenon in patients with acute ST-segment elevation myocardial infarction after direct 
PCI. Exp Ther Med. 2018; 15:3940-3946.

33. Bangalore S, Guo Y, Samadashvili Z, Hannan EL. Outcomes With Complete Versus Incomplete Revascularization in Patients With Multivessel Coronary Disease Undergoing Percutaneous Coronary Intervention With Everolimus Eluting Stents. Am J Cardiol. 2020; 125:362-369.

34. Lee WC, Chen TY, Chen CJ, Yang CH, Fang CY, Wu CJ, et al. The effect of complete revascularization in patients with ST-segment elevation myocardial infarction with Killip class $\geq$ III. Coron Artery Dis. 2020; 31:13-19.

35. Ryder S, Fox K, Rane P, Armstrong N, Wei CY, Deshpande S, et al. A Systematic Review of Direct Cardiovascular Event Costs: An International Perspective. Pharmacoeconomics. 2019; 37:895-919.

36. Song XT, Du MY, Yuan F, Lü SZ. Cost-utility analysis of percutaneous coronary intervention in 13 cities of China. Zhonghua Xin Xue Guan Bing Za Zhi. 2010; 38:484-487.

37. Burns RJ, Gibbons RJ, Yi Q, Roberts RS, Miller TD, Schaer GL, et al. The relationships of left ventricular ejection fraction, end-systolic volume index and infarct size to six-month mortality after hospital discharge following myocardial infarction treated by thrombolysis. J Am Coll Cardiol. 2002; 39:30-36.

38. Wu E, Ortiz JT, Tejedor P, Lee DC, Bucciarelli-Ducci C, Kansal P, et al. Infarct size by contrast enhanced cardiac magnetic resonance is a stronger predictor of outcomes than left ventricular ejection fraction or end-systolic volume index: prospective cohort study. Heart. 2008; 94:730-736.

39. Mohammad MA, Koul S, Smith JG, Noc M, Lang I, Holzer M, et al. Predictive Value of High-Sensitivity Troponin T for Systolic Dysfunction and Infarct Size (Six Months) After ST-Elevation Myocardial Infarction. Am J Cardiol. 2018; 122:735-743.

40. Park KC, Gaze DC, Collinson PO, Marber MS. Cardiac troponins: from myocardial infarction to chronic disease. Cardiovasc Res. 2017; 113:1708-1718.

41. Farnsworth CW, Bailey AL, Jaffe AS, Scott MG. Diagnostic concordance between NT-proBNP and BNP for suspected heart failure. Clin Biochem. 2018; 59:50-55.

42. García-Alvarez A, Regueiro A, Hernández J, Kasa G, Sitges M, Bosch X, et al. Additional value of Btype natriuretic peptide on discrimination of patients at risk for mortality after a non-ST-segment elevation acute coronary syndrome. Eur Heart J Acute Cardiovasc Care. 2014; 3:132-140.

43. de Lemos JA, Morrow DA, Bentley JH, Omland T, Sabatine MS, McCabe CH, et al. The prognostic value of B-type natriuretic peptide in patients with acute coronary syndromes. N Engl J Med. 2001; 345:1014-1021.

44. Jernberg T, Stridsberg M, Venge P, Lindahl B. N-terminal pro brain natriuretic peptide on admission for early risk stratification of patients with chest pain and no ST-segment elevation. J Am Coll Cardiol. $2002 ; 40: 437-445$.

45. Pedersen SS, van Domburg RT, Larsen ML. The effect of low social support on short-term prognosis in patients following a first myocardial infarction. Scand J Psychol. 2004; 45:313-318.

46. Abbas CC, Schmid JP, Guler E, Wiedemar L, Begré S, Saner H, et al. Trajectory of posttraumatic stress disorder caused by myocardial infarction: a two-year follow-up study. Int J Psychiatry Med. 2009; 
Figures

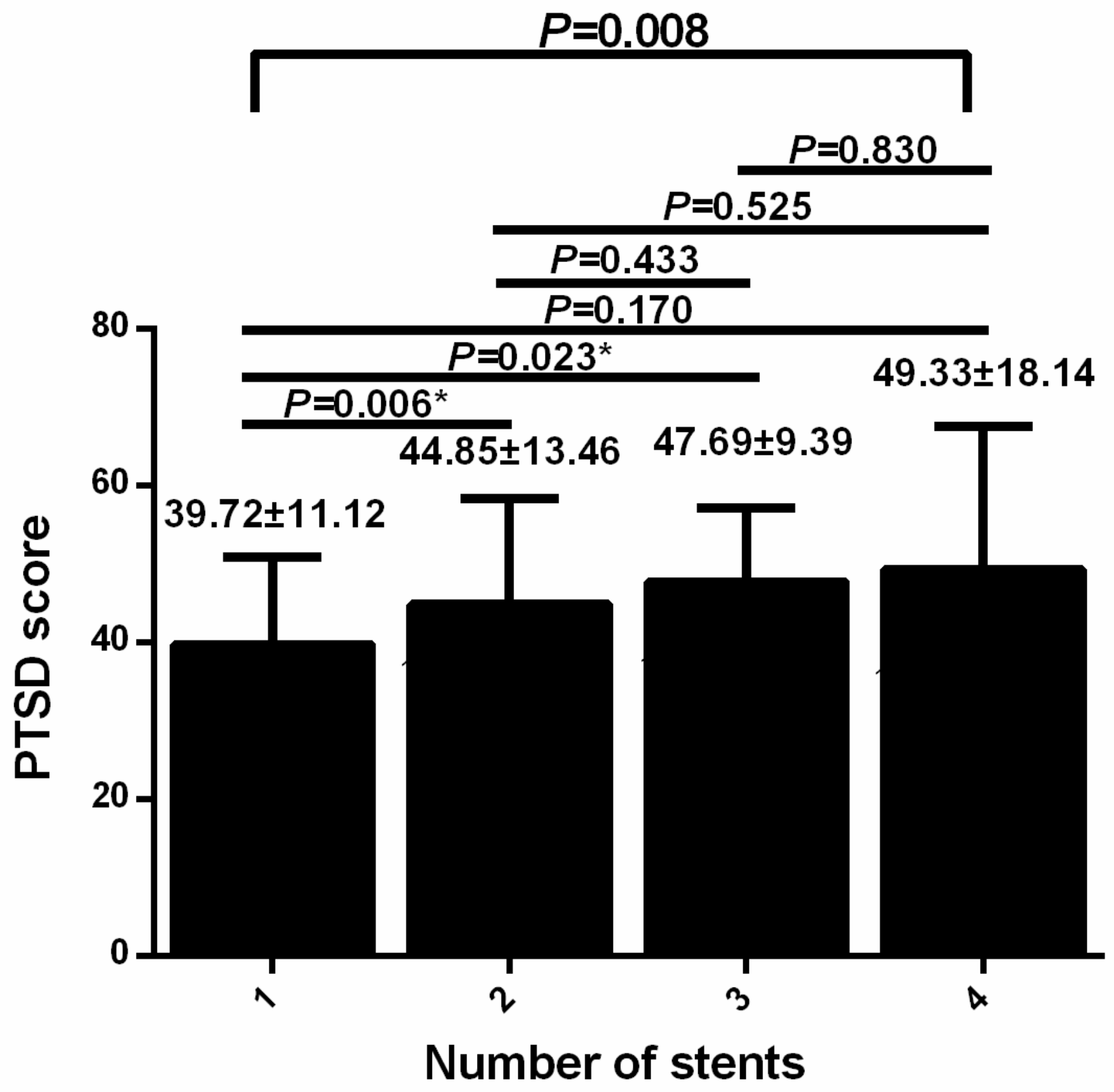

Figure 1

PTSD score in acute MI patients with different number of stents implanted. 


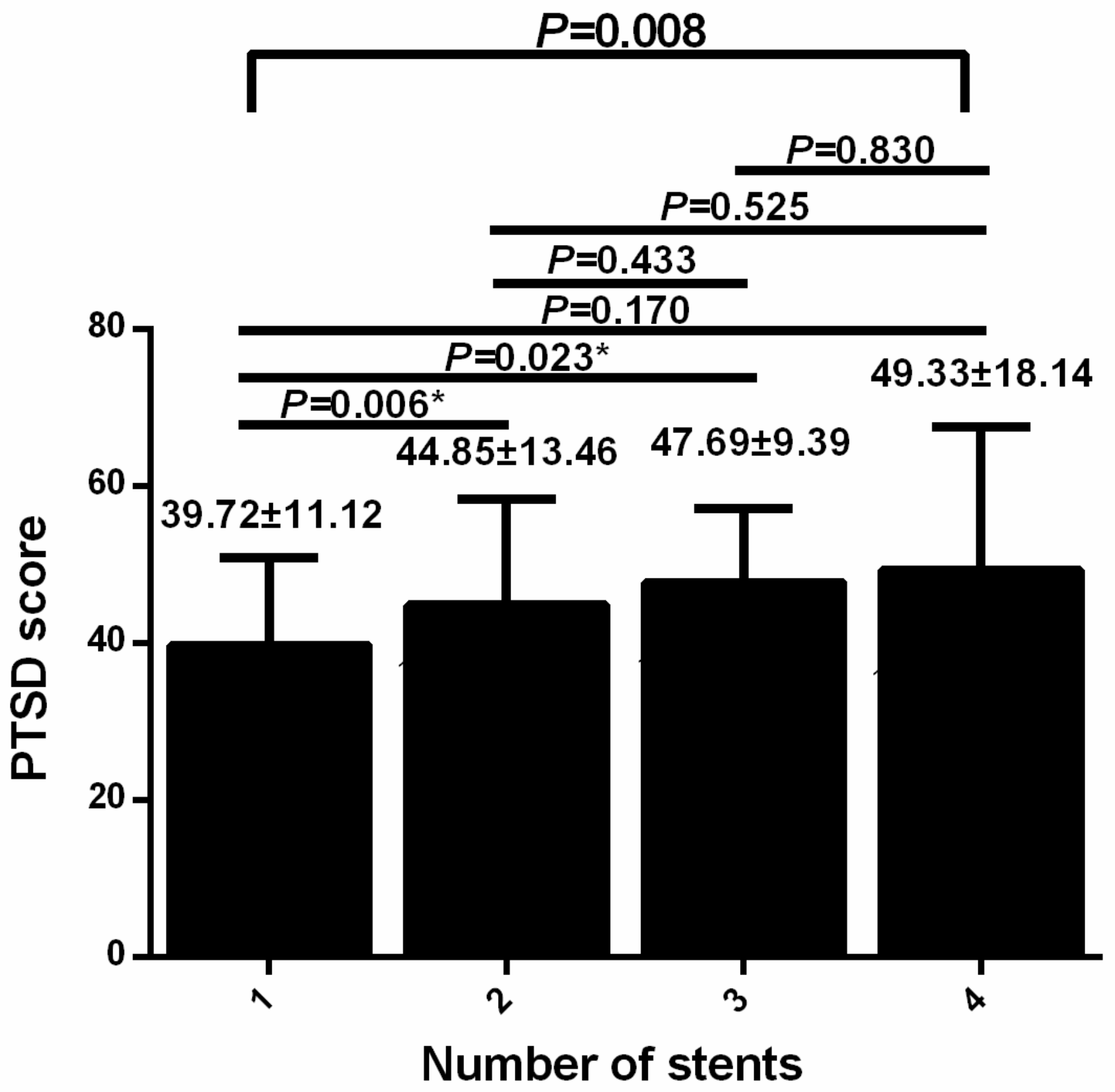

Figure 1

PTSD score in acute MI patients with different number of stents implanted. 